\title{
Esthetic restoration of anterior teeth using temporization material in deciduous dentition: A case report
}

\author{
Teena Gupta ${ }^{1}$, Manjul Mehra ${ }^{2}$, Gunmeen Sadana $^{3}$, Muskaan Nischal $^{4^{*}}$ \\ ${ }^{1}$ Professor, ${ }^{2}$ Reader, ${ }^{3} \mathrm{HOD},{ }^{4}$ Post Graduate Student, Dept. of Pediatric and Preventive Dentistry, Sri Guru Ram Das Institute of Dental \\ Sciences and Research, Amritsar, Punjab, India \\ *Corresponding Author: Muskaan Nischal \\ Email: muskaannischal@gmail.com
}

\begin{abstract}
Dental caries is a major health problem in pre school, primary school going children and adolesecents. However, every individual is susceptible to this ailment during the course of its life. A number of treatment modalities are available for restoring primary incisors which include pre-veneered stainless steel crowns, polycarbonate crowns, resin strip crowns and zirconia crowns. This case report demonstrates a clinical technique for restoring primary incisors using a new temporization material.
\end{abstract}

Keywords: Dental caries, Crowns, Temporization material, Primary incisors.

\section{Introduction}

Esthetic rehabilition of deciduous teeth is one of the most challenging encounters a dentist faces in day to day practice. Despite of the availability of infinite number of esthetic materials, selection of an ideal material for restoration of primary anterior teeth remains an uphill task ${ }^{1}$. With the innovations in the field of esthetic dentistry, newer dental materials and techniques are emerging into clinical practice. $^{2}$

Composite resin strip crowns are the most commonly used crowns in pediatric dentistry for restoring anterior teeth $^{3}$. Despite having good esthetics and higher success rate, the results can still be compromised due to difficulty in maintaining isolation in children, shorter clinical crowns and technique sensitivity ${ }^{4}$.Other esthetic crowns include prefabricated zirconia, pre veneered stainless steel and polycarbonate crowns. These crowns exhibit superior esthetics and better retention, but difficult marginal adaptation to the tooth and higher cost are their major drawbacks.

Hence, an ideal material should be esthetically superior, durable, cost effective and easily adaptable. With the recent advancements in restorative dentistry, customized chair side full-coronal restorations have been introduced, which contain bis-acryl composite-based material for temporization. Luxa crown is one such temporization material which is a self curing composite for fabrication of semi permanent crowns and bridges. Though it is often used for temporization of permanent teeth, but it can also be considered as a treatment option for restoring grossly decayed or traumatized deciduous teeth. The unique Luxa Crowns are simple, quick and cost-effective for the fabrication of long-lasting crowns. They offer an excellent and reliable alternative to lab processed crowns. The material has brilliant flexural strength, exceptional fracture toughness ensuring stable and long-term provisionals. This case report describes clinical technique of using a temporization material for restorations in primary anterior teeth.

\section{Case Report}

A 4 year old male patient reported to the Department of Pediatric and Preventive Dentistry with the chief complaint of decayed upper front teeth. Patient gave a history of sensitivity to sweets six months back after which the patient was asymptomatic. On examination, 51, 52, 61, 62 were found to be carious. Radiographic examination showed pulpal involvement with respect to 51, 52, 61, 62. (Fig. 1,2)

\section{Procedure}

Step 1: Caries excavation, pulpectomy and composite core build-up (wherever necessary): Initially, caries was excavated followed by pulpectomy and composite corebuild-up.

Step 2: Tooth preparation: Crown cutting was done in such a way that $1.5 \mathrm{~mm}$ of tooth structure was removed uniformly from all sides (Fig. 4)

Step 3: Selection of strip crowns: An appropriate-sized strip crown was selected according to mesiodistal width to fabricate the crown.(Fig. 5,6)

Step 4: Strip crown loading: Shade selection was done in accordance with the adjacent teeth and strip crown was loaded with luxa crown material using automix syringe. Loaded strip crowns were then placed on the prepared tooth within 40 seconds and removed while the material was still in elastic stage (1.45-2.20 minutes after start of mixing) (Fig. 7)

Step 5: Tearing of the strip crown: Material was then allowed to set extraorally, and strip crown was peeled off.

Step 6: Crown cementation: The finished crown was cemented over the prepared crown using Resin modified glass ionomer Relyx lutting 2 cement. Occlusion was checked and adjusted accordingly ${ }^{6}$. Satisfactory results were obtained with good esthetics. (Fig. 8) 


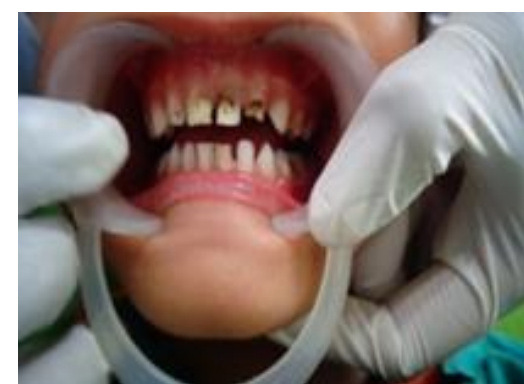

Fig 1: Pre-operative photograph showing carious 51, 52, 61, 62

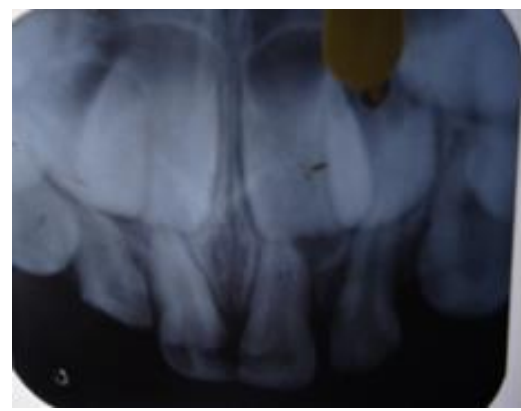

Fig 2: Pre-operative radiograph showing pulpal involvement $51,52,61,62$

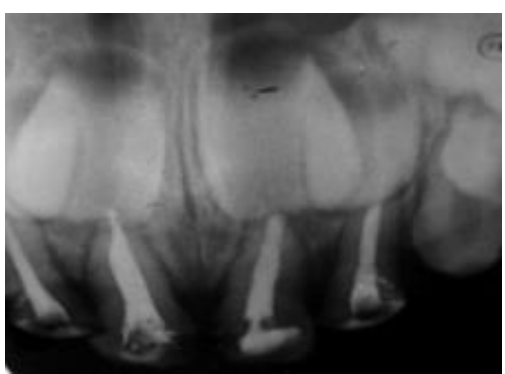

Fig 3: Radiograph showing obturation 51, 52, 61, 62

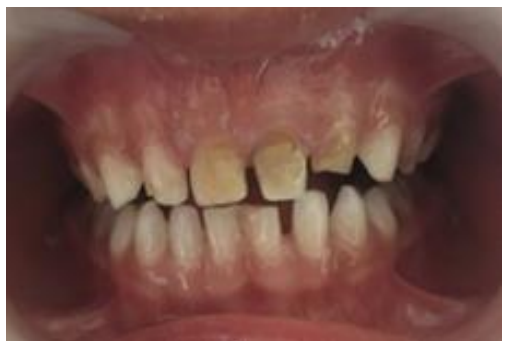

Fig 4: Tooth preparation done 51,61

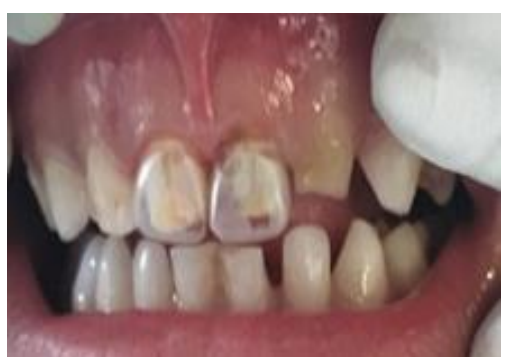

Fig 5: Selection of appropriate-sized strip crowns 51,61

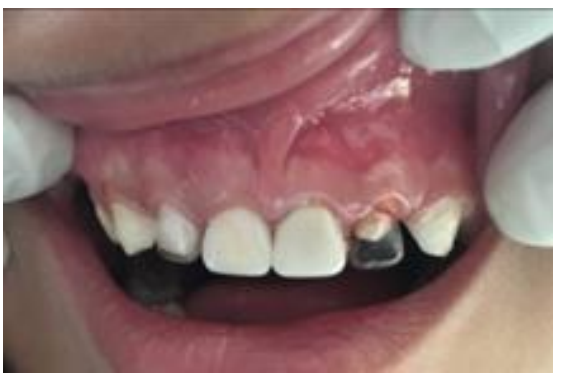

Fig 6: Strip crown adaptation on 52,62

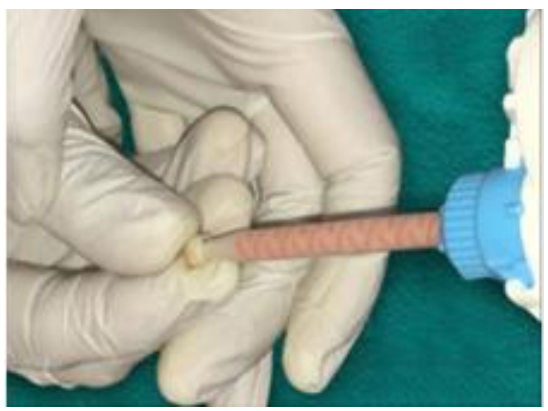

Fig 7: Strip crown filled with Luxa crown material

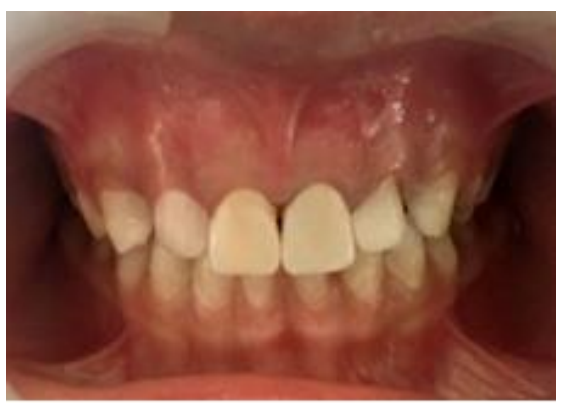

Fig 8: Post- operative photograph showing luxa crowns $51,52,61,62$

\section{Discussion}

Dental crowns can either be bonded to tooth structure or cemented to prepared teeth using a luting agent. Both these methods have their own advantages and limitations. Bonded strip crowns have been the material of choice for restoring primary teeth, mainly because of their good esthetics and easy repair. However these crowns may get discoloured, fracture or dislodge over a period of time due to lack of appropriate bonding and less surface area of prepared tooth. ${ }^{7}$

A variety of crowns are available in dentistry which have better esthetics and durability than bonded crowns. Zirconia crowns and Preveneered Stainless Steel crowns are key examples of esthetic crowns used in paediatric dentistry these days ${ }^{8}$. Despite of their advantages, these materials are challenging to work as they have limited shade selection, difficulty in modifying the shape of the crown and their higher cost. ${ }^{9}$

The crowns fabricated in the present case have used temporization material. The rationale behind using this material for crown fabrication in primary teeth is that, these teeth need to be retained only for a limited period of time, so a material which is durable enough for "this time period" 
could prove to be a appropriate alternative. This bisacrylate-based temporization material (Luxa Crowns) has good dimensional stability, flexural strength and better colour matching thus making it a suitable choice for esthetic restoration of primary carious teeth. The margins and the final restoration ensured better adaption and exhibited good and acceptable immediate esthetics ${ }^{6}$.

\section{Conclusion}

Treatment options available to restore grossly multilated primary anterior teeth include resin strip crowns, preveneered stainless crowns, zirconia crowns. These materials despite being superior in esthetics have their own disadvantages. Luxa crowns can be a good clinical alternative to restore primary teeth, because of its good esthetics, high fracture toughness and less polymerization shrinkage. However, long-term clinical studies should be carried out to advocate it to be a material of choice for restoring primary anterior teeth.

\section{Source of funding}

None.

\section{Conflict of interest}

None.

\section{References}

1. Messer L.B, \& Levering N.J. The durability of primary molar restorations: II. Observations and predictions of success of stainless steel crowns. Pediatr Dent 1998;10(2):81-5.
2. Abu-Hussein M, Watted N, Abdulgani Azz, Abu-Shilabayeh H. Anterior dental esthetics in primary teeth. Int J Public Health Res 2015;4(1),25-36

3. Ram D, Fuks AB. Clinical performance of resin-bonded composite strip crowns in primary incisors: A retrospective study Int J Paediatr Dent 2006;16:49-54.

4. Waggoner WF. Restoring primary anterior teeth. Pediatr Dent 2002;24:511-6.

5. Waggoner WF. Restoring primary anterior teeth: updated for 2014. Pediatr Dent 2015;37(2):163-70.[PubMed]

6. Gugnani N, Pandit IK, Gupta M, Nagpal J. Esthetic Rehabilitation of Primary Anterior Teeth using Temporization Material: A Novel Approach. Int J Clin Pediatr Dent 2017;10(1):111-4.

7. Duhan H, Pandit IK, Srivastava N, Gugnani N, Gupta M, Kochhar GK et al. Clinical comparison of various esthetic restorative options for coronal build-up of primary anterior teeth. Dent Res J (Isfahan) 2015;12(6):574-80.

8. Dhar V,Hsu KL, Coll JA, Ginsberg E, Ball BM, Chhibber S et al. Evidence-based update of pediatric dental restorative procedures: dental materials. J Clin Pediatr Dent 2015;39(4):303-10.

9. Clark L, Wells MH, Harris EF, Lou J. Comparison of amount of primary tooth reduction required for anterior and posterior zirconia and stainless steel crowns. Pediatr Dent 2016;38(1):42-6.

How to cite: Gupta T, Mehra M, Sadana G, Nischal M. Esthetic restoration of anterior teeth using temporization material in deciduous dentition: A case report. Indian $J$ Conserv Endod 2020;5(1):30-2. 